\title{
Target delivery of MYCN siRNA by folate-nanoliposomes delivery system in a metastatic neuroblastoma model
}

\author{
Qiqi Zhu, Chen Feng, Weiwei Liao, Yan Zhang and Suoqin Tang ${ }^{*}$
}

\begin{abstract}
Background: Folate-nanoliposomes delivery system has emerged recently as a specific and safety delivery method and gradually used as the carrier of a variety kinds of drugs including compounds, plasmids and siRNAs.

Methods: In this study, we established a bone marrow and bone metastasis xenograft mouse model by injecting the LA-N-5 cell into the bone marrow cavity. Fluorescence microscopy, TUNEL Assay, Quantitative RT-PCR and western blot were conducted to analysis the distribution of folate-nanoliposomes entrapped MYCN (V-myc myelocytomatosis viral related oncogene) siRNA in mice and the relevant suppression effect.

Results: The folate-nanoliposomes entrapped MYCN siRNA can be specifically distributed in tumor tissues. Further study shows that folate-nanoliposomes entrapped MYCN siRNA lead to MYCN mRNA expression significantly down-regulated $(>50 \%$, and $p<0.05)$ compared with negative control siRNA treatment. MYCN protein expression was inhibited about $60 \%$ in vivo, thus induced tumor cell apoptosis markedly.
\end{abstract}

Conclusion: This study point to a new way for treatment of metastatic neuroblastoma and could widen the application of folate-nanoliposomes delivery system in tumor therapy.

Keywords: Folate-nanoliposomes, Metastatic neuroblastoma, MYCN, siRNA

\section{Introduction}

Neuroblastoma is the most common extracranial solid tumor occurring in children, which accounts for about $15 \%$ of all childhood cancer deaths [1,2]. It is generally accepted that the amplification of the MYCN protooncogene is highly relevant to the genesis and prognosis of neuroblastoma [3,4]. MYCN is an important member of the myc family that includes 3 strong oncogenes, MYC, MYCN, and MYCL [5]. Targeting MYCN gene has developed into a promising therapeutic strategy [6-8]. Small interference RNA (siRNA) is synthetic short double-stranded RNA, which can induce the destruction of homologous mRNA when introduced into a cell [9]. siRNA has been developed into an effective tool for suppressing target proteins expression by specifically digesting their mRNAs [10]. siRNAs have been widely investigated

\footnotetext{
* Correspondence: suoqin@yahoo.com

Department of Pediatrics, Hainan Brach of Chinese PLA General Hospital, Haitang Bay, Sanya, Hainan Province 572013, China
}

as therapeutic agents to treat a wide range of human diseases including neuroblastoma $[7,11]$.

Folate, a nontoxic low-weigh compound, is vital for tumor cell proliferation and survival. Studies show that tumor cells can express 200-folds more folate receptor on the membrane than normal cells, which is accordance to the high intake of folate in tumor cells. Folate receptor is overexpressed in a wide range of human cancer cells, including ovarian cancer, endometrial cancer, head and neck cancers, myeloid leukaemia, and some pediatric cancers [12]. Folate conjugating on liposomes with entrapped drugs [13-16] or plasmids [17-20] has been used successfully to deliver drugs to folate-receptor -expressing cancer cells. Our previous study had revealed that the folate receptor was highly expressed on the membrane of LA-N-5 neuroblastoma cells. In this study, we want to further investigate whether folate receptor-targeted liposome can act as a good delivery tool of MYCN siRNA and exert a satisfying therapeutic effect on neuroblastoma.
C Biomed Central

(c) 2013 Zhu et al.; licensee BioMed Central Ltd. This is an Open Access article distributed under the terms of the Creative Commons Attribution License (http://creativecommons.org/licenses/by/2.0), which permits unrestricted use, distribution, and reproduction in any medium, provided the original work is properly cited. 
In this study, we established a bone marrow and bone metastasis xenograft mouse model by injecting the LAN-5 cell into the bone marrow cavity. Then we examined whether folate-nanoliposomes entrapped MYCN siRNA can specifically distribute to tumor tissues and suppress MYCN gene expression as well as induce apoptosis in neuroblastoma cells.

\section{Materials and methods}

Animals

$\mathrm{BALB} / \mathrm{c}$ nude mice ( $4 \mathrm{wk}$ ) were used for all experiments. All animals were housed in the Experimental Animal Centre of PLA General Hospital, and all procedures were approved by the Institutional Animal Care and Use Committee of PLA General Hospital.

\section{Cell culture}

LA-N-5 neuroblastoma cell was the generous gift of Dr. Robert Seeger from Children's Hospital Los Angeles, and the cells were grown in RPMI 1640 medium (GIBCO BRL, USA) containing 15\% fetal bovine serum (Hyclone, USA), $2 \mathrm{mmol} / \mathrm{L}$ l-glutamine, $100 \mathrm{IU} / \mathrm{ml}$ penicillin G and $100 \mu \mathrm{g} / \mathrm{mL}$ streptomycin (all were from Huamei Company, China) in a humidified $5 \% \mathrm{CO}_{2}$ and $95 \%$ air atmosphere at $37^{\circ} \mathrm{C}$.

\section{Establishment of the bone marrow and bone metastasis xenograft mouse model}

Previously described procedure was introduced in the current study [21,22]. Briefly, LA-N-5 neuroblastoma cells were harvested and washed by centrifugation and resuspended in cold serum-free medium prior to injection. Mice were immobilized in a restraining device, and cells $\left(10^{5}\right.$ cells in $\left.5 \mu \mathrm{l}\right)$ were injected into the bone marrow cavity of the femoral proximal metaphysis. About five weeks later, the diameters of tumors can be up to $5 \mathrm{~mm}$ and the bone metastasis model is successfully established.

\section{Preparation of the folate-nanoliposome entrapped MYCN siRNA}

The folate-nanoliposome entrapped MYCN siRNA with Cy-3 fluorescence tag was the generous gift from Dr. Robert J. Lee (Ohio State University, College of Pharmacy). siRNA sequences were as follows: MYCN siRNA sense: 5'-CGGAGAUGCUGCUUGAGAA dtdt-3', antisense: 5'-UUCUCAAGCAGCAUCUCCG dtdt-3'; the negative control siRNA: sense: 5 '-UUCUCCGAACGU GUACGU dtdt-3', anti-sense: 5' -ACGUGACAC GUU CGGAGAA dtdt-3'.

\section{siRNA distribution analysis and gene therapy}

For siRNA distribution analysis, LA-N-5 neuroblastoma cells were injected into mice bone marrow cavity to establish the bone marrow and bone metastasis xenograft models. Then the folate-nanoliposome entrapped MYCN siRNA with Cy3 tag (3 $\mathrm{mg} / \mathrm{kg}$ ) was injected into mice via lateral tail vein, and mice were sacrificed 8 hours after injection. Tumors of femur and other indicated organs (heart, lung, liver, kidney) were harvested, embedded in optimum cutting temperature compound (OCT) and sectioned into $4 \mu \mathrm{m}$ frozen sections. Tissues sections were observed under fluorescence microscopy (stimulating wavelength, $554 \mathrm{~nm}$ ). Three views of each organ were chosen randomly and subjected to calculate the average integrated optical density (IOD) with Image pro plus 6.0 Software. In the gene therapy experiment, mice were divided into two groups $(6$ mice for each group). LA-N-5 neuroblastoma cells were injected into mice bone marrow cavity to establish the bone marrow and bone metastasis xenograft model. Then the folatenanoliposome entrapped MYCN siRNA with Cy3 tag $(3 \mathrm{mg} / \mathrm{kg} / \mathrm{d})$ were injected into one group of mice by lateral tail vein. The other group of mice were injected with folate-nanoliposome entrapped the control siRNA (3 mg/kg/d). Mice were sacrificed at the sixth day after 5 injections of folate-nanoliposome entrapped siRNAs. Tumors frozen sections were analyzed by TUNEL Assay.

\section{Quantitative RT-PCR analysis}

The cells were harvested and RNA was extracted by using the Ultrapure RNA Kit (CWbio.Co.Ltd). Briefly, cells were lysed in RLT buffer and RNA was purified according to the manufacturer's instructions. RNase-free DNase set (CWbio.Co.Ltd) was used to remove any contaminating genomic DNA. The cDNA was synthesized using HiFi-MMLV cDNA Kit (CWbio.Co.Ltd). The primer sequences for MYCN were: $5^{\prime}$-CTCAGTACCTCC GGAGAG-3' (sense) and 5'-GGCATCGTIGAGGATC3' (antisense). The primer sequences for $\mathrm{GAPDH}$ were:5' -TGCACCACCAACTGCTTAGC-3' (sense) and 5'-GGCATGGACTGTGGTCATGAG-3' (antisense). Realtime PCR was performed on an Roche LightCycler 480IIsystem, using LightCycler 480 SYBR GreenIMaster (Roche). Each sample was determined in triplicate. MYCN mRNA expression was calculated as MYCN copies/GAPDH copies. Relative standard curve method was used to determine the relative mRNA expression of MYCN gene.

\section{Western blot}

Tumor frozen samples from each mouse in a same group were mixed and total protein was extracted. Proteins were separated by a precast $4-12 \%$ SDS-PAGE gel (Sigma) and electrophoretically transferred to a PVDF membrane, followed by incubation with anti- $\beta$-actin antibody (1/2000 ab3280 Abcam, Cambridge, MA, USA) and anti-n-Myc antibody [NCM II 100] (1:1000 ab16898 Abcam, Cambridge, MA, USA). Protein bands were 
detected with ECL reagents (Amersham Biosciences, Buchinghamshire, UK) and visualized by autoradiography.

\section{TUNEL assay}

Briefly, frozen tumor samples were cut on a cryostat and got $4 \mu \mathrm{m}$-thick sections. Slices were fixed with acetone and soaked in 3\% hydrogen peroxide-methanol solution for $20 \mathrm{~min}$, then rinsed in PBS for 3 times. Fixed sections were incubated with proteinase $\mathrm{K}(20 \mu \mathrm{g} / \mathrm{ml})$ for $20 \mathrm{~min}$ at $37^{\circ} \mathrm{C}$ and washed with TBS for 3 times. Then they were incubated with TdT buffer containing digoxigenin labelled desoxyuridinetriphosphate (DIG-UTP) and dATP for $2 \mathrm{~h}$ at $37^{\circ} \mathrm{C}$, and immersed in stop solution for $30 \mathrm{~min}$ at room temperature. After washing, the sections were incubated with strept avidin-biotin-peroxidase complex $(\mathrm{SABC})$ antibody solution for $60 \mathrm{~min}$ at $37^{\circ} \mathrm{C}$, followed by incubation with DAB for $20 \mathrm{~min}$. Slices were counterstained with hematoxylin and examined with a fluorescence microscope.

\section{Statistical analysis}

All experiments were performed at least in triplicate and data are expressed as means \pm SEM. Statistical differences were analyzed by two-tailed $t$ test. $\mathrm{P}<0.05$ was considered statistically significant.

\section{Results}

Folate-nanoliposome entrapped MYCN siRNA is specifically distributed in tumor tissues

LA-N-5 neuroblastoma cells were injected into mice bone marrow cavity to establish the bone marrow and bone metastasis xenograft model. Then mice were injected with the folate-nanoliposome entrapped $\mathrm{MYCN}$ siRNA with Cy3 tag (Figure 1) by tail vein, and sacrificed 8 hours after injection. Tissues sections were observed under fluorescence microscopy and showed that $\mathrm{Cy} 3$ fluorescence was very bright in tumors in bones (Figure 2A, B). Liver, kidney, heart and lung tissues have weak or no visible fluorescence (Figure 2A, B). This indicates that folate-nanoliposome entrapped MYCN siRNA is specifically distributed in tumor tissues.

In vivo gene silencing effect of folate-nanoliposome entrapped MYCN siRNA in LA-N-5 neuroblastoma

Mice were injected (i.v.) with folate-nanoliposome entrapped MYCN siRNA or control siRNA for 5 days and gene silencing effect of MYCN siRNA in LA-N-5 neuroblastoma were examined by real-time PCR and Western blot. As shown in Figure 3A, MYCN mRNA expression was significant down-regulated $(>50 \%)$ by folate-nanoliposome entrapped MYCN siRNA compared to negative control siRNA treatment $(\mathrm{p}<0.01)$. Western blot result showed MYCN protein expression was about $60 \%$ inhibited by

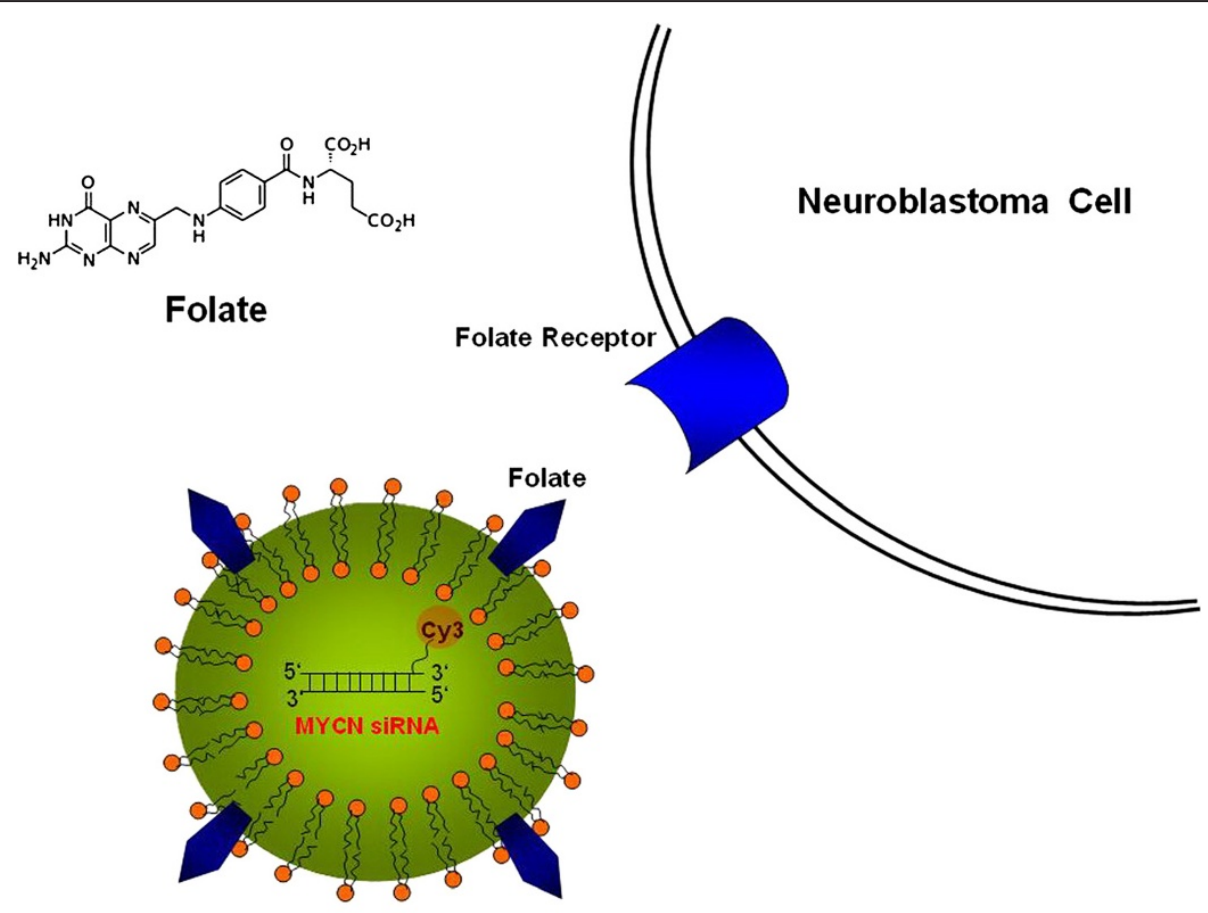

Folate-Nanoliposomes Entrapped MYCN siRNA

Figure 1 A diagram of target delivery of MYCN siRNA by folate-nanoliposomes. 

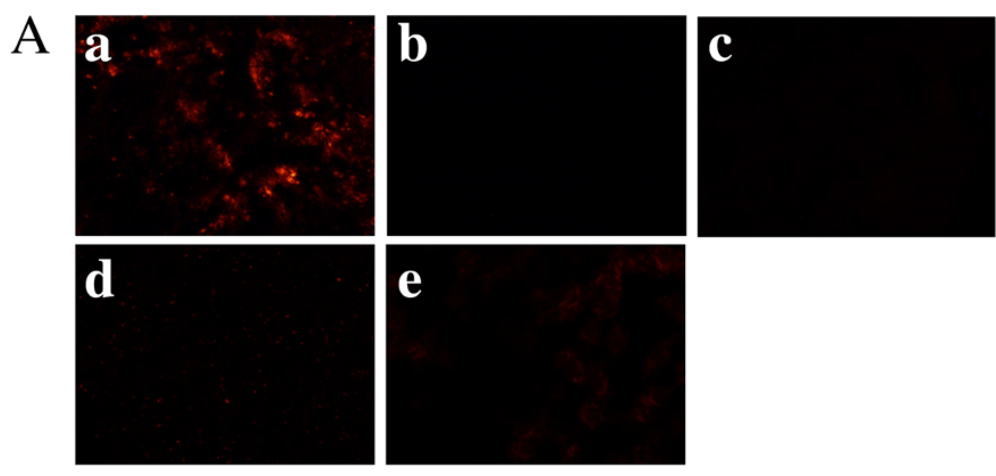

B

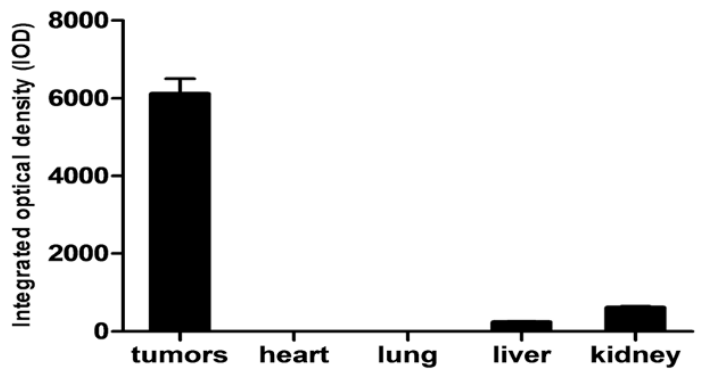

Figure 2 Distribution of folate-nanoliposome entrapped MYCN siRNA: A, Cy3 fluorescence of different tissues. $\mathbf{a}$, tumors tissue; $\mathbf{b}$, heart; c, lung; $\mathbf{d}$, liver; $\mathbf{e}$, kidney. This graph is one representative result of three views; B, Quantitative analysis of fluorescence intensity of each tissue. Fluorescence intensity was expressed as integrated optical density (IOD). Results are expressed as means \pm SE.

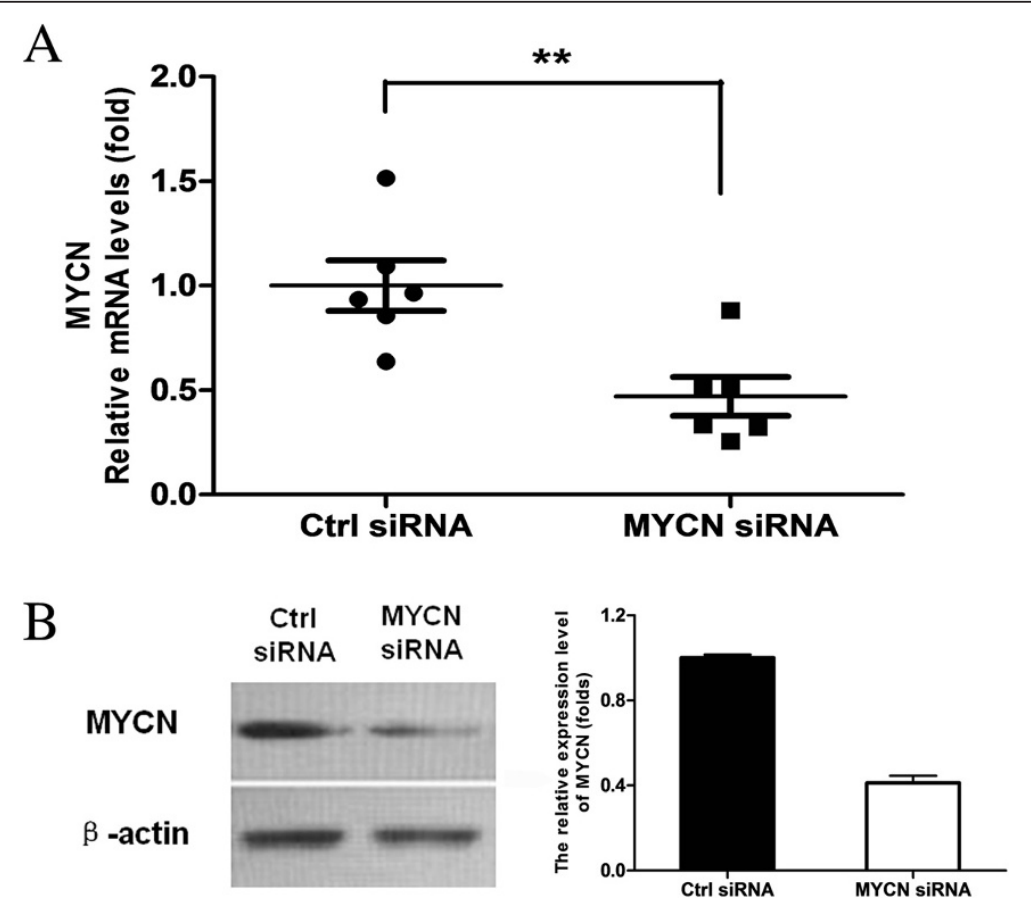

Figure 3 The in vivo gene silencing effect of folate-nanoliposome entrapped MYCN siRNA in LA-N-5 neuroblastoma: A, Quantitative RT-PCR analysis of MYCN gene expression. Results are normalized to GAPDH expression and are presented as fold increases over the control. 6 mice each group, ${ }^{*} P<0.05,{ }^{*} \mathrm{P}<0.01 ; \mathbf{B}$, Western blot analysis of MYCN gene expression. Frozen tumor samples of each mouse in a same group were mixed and analyzed by Western blot. The right graph is a quantitative analysis of the left one. 

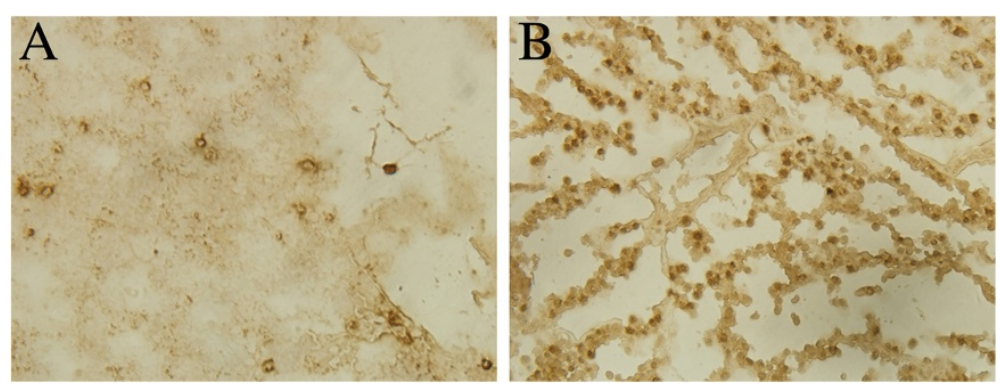

Figure 4 TUNEL assay of LA-N-5 neuroblastoma: A, folate-nanoliposome entrapped control siRNA group; B, folate-nanoliposome entrapped MYCN siRNA group.

folate-nanoliposome entrapped MYCN siRNA (Figure 3B). These data demonstrate that systematic injection of folatenanoliposome entrapped MYCN siRNA can silence MYCN gene expression of tumor tissues efficiently.

\section{The pro-apoptotic effect of folate-nanoliposome entrapped MYCN siRNA in neuroblastoma}

Gene therapeutic effect of folate-nanoliposome entrapped MYCN siRNA was evaluated by TUNEL assay of neuroblastoma. As shown in Figure 4, MYCN siRNA treatment group caused much more TUNEL positive cells than control siRNA treatment group. This indicates that folate-nanoliposome entrapped MYCN siRNA treatment can lead to apoptosis of neuroblastoma in vivo.

\section{Discussion}

Our results showed MYCN knockdown induces apoptosis of metastatic neuroblastoma in vivo, MYCN gene, located on the short arm of chromosome 2, is only expressed during the stages of embryonic development of the nervous system, kidney, lung and spleen [23]. MYCN gene is considered a proto-oncogene associated with the malignant tumors growth [24-26]. Since MYCN gene amplification plays a key role in the neuroblastoma progression, inhibition the MYCN gene expression becomes a probable strategy for high-risk neuroblastoma therapy. Studies by other groups [27-29] have demonstrated that inhibition of MYCN gene expression in neuroblastoma cells makes cell cycle arrest at G1 phase, and promotes tumor cell apoptosis or differentiation into neural cells. The MYCN gene is a promising drug target for treating peripheral and central nervous system tumors [30].

Although the therapeutic strategy targeting MYCN in vivo by siRNA is attractive, the traditional drugs delivery methods seem to be nonspecific and toxic [31]. The folate receptor-targeted liposome delivery system has emerged recently as a specific and safety delivery method and become the frontier of drugs delivery. This study was designed to examine the specificity and efficacy of folate-nanoliposome entrapped MYCN siRNA in treatment of metastatic neuroblastoma, showing that MYCN siRNA was distributed specically in tumor tissues under the direction of folate-folate receptor interaction and further silences MYCN gene expression both in mRNA and protein levels and finally induces apoptosis of neuroblastoma cells. This indicates that folatenanoliposome entrapped MYCN siRNA could be used in future gene therapy of neuroblastoma. Of note, the in vivo gene knockdown efficiency is up to $60 \%$ in protein level, which is much higher than that of traditional methods such as lipofection or calcium-phosphate transfection [31].

This study points to a new way for treatment of metastatic neuroblastoma and widen the application of folate-nanoliposomes delivery system in tumor therapy. The high specificity, efficiency and safety make folate receptor-targeted liposome delivery system a killer mace in siRNAs-mediated cancer gene therapy.

\section{Abbreviations}

siRNA: Small interference RNA; IOD: Integrated optical density; DIGUTP: Digoxigenin labelled desoxyuridinetriphosphate; SABC: Strept avidinbiotin-peroxidase complex.

\section{Competing interests}

The authors declare that they have no competing interests.

\section{Authors' contributions}

The work presented here was carried out in collaboration between all authors. ST defined the research theme. QZ designed methods and experiments, carried out the laboratory experiments, CF and WL analyzed the data, interpreted the results. YZ co-worked on associated data collection and their interpretation. All authors read and approved the final manuscript.

\section{Acknowledgements}

The work was supported by the National High Technology Research and Development Program of China (863 Program). Fund number: 2012AA020804

Received: 16 March 2013 Accepted: 21 June 2013

Published: 27 June 2013

\section{References}

1. Schor NF: Neuroblastoma as a neurobiological disease. J Neurooncol 1999, 41:159-166

2. Hogarty MD, Maris JM: PI3King On MYCN to improve neuroblastoma therapeutics. Cancer Cell 2012, 21:145-147. 
3. Schwab M, Westermann F, Hero B, Berthold F: Neuroblastoma: biology and molecular and chromosomal pathology. Lancet Oncol 2003, 4:472-480.

4. Suenaga Y, Kaneko Y, Matsumoto D, Hossain MS, Ozaki T, Nakagawara A Positive auto-regulation of MYCN in human neuroblastoma. Biochem Biophys Res Commun 2009, 390:21-26.

5. Cole MD, McMahon SB: The Myc oncoprotein: a critical evaluation of transactivation and target gene regulation. Oncogene 1999, 18:2916.

6. Aagaard L, Rossi JJ: RNAi therapeutics: principles, prospects and challenges. Adv Drug Deliv Rev 2007, 59:75-86.

7. Jiang $R$, Xue $S$, Jin Z: Stable knockdown of MYCN by lentivirus-based RNAi inhibits human neuroblastoma cells growth in vitro and in vivo. Biochem Biophys Res Commun 2011, 410:364-370.

8. Lovén J, Zinin N, Wahlström T, Müller I, Brodin P, Fredlund E, Ribacke U, Pivarcsi A, Påhlman S, Henriksson M: MYCN-regulated microRNAs repress estrogen receptor-a (ESR1) expression and neuronal differentiation in human neuroblastoma. Proc Natl Acad Sci 2010, 107:1553-1558

9. Heo I, Kim VN: Regulating the regulators: posttranslational modifications of RNA silencing factors. Cell 2009, 139:28-31.

10. Fire A, XU SQ, Montgomery MK, Kostas SA, Driver SE, Mello CC: Potent and specific genetic interference by double-stranded RNA in Caenorhabditis elegans. Nature 1998, 391:806-811.

11. Talmadge JE, Singh RK, Fidler IJ, Raz A: Murine models to evaluate novel and conventional therapeutic strategies for cancer. Am J Pathol 2007, 170:793.

12. Daldrup-Link HE, Hawkins RA, Meier R, Goldsby RE, Artemov D: Receptor imaging of pediatric tumors: clinical practice and new developments. Pediatr Radiol 2008, 38:1154-1161.

13. Lee RJ, Low PS: Delivery of liposomes into cultured KB cells via folate receptor-mediated endocytosis. J Biol Chem 1994, 269:3198-3204.

14. Rui Y, Wang S, Philip S, Thompson DH: Diplasmenylcholine-folate liposomes: an efficient vehicle for intracellular drug delivery. J Am Chem Soc 1998, 120:11213-11218.

15. Gabizon A, Horowitz AT, Goren D, Tzemach D, Mandelbaum-Shavit F, Qazen MM, Zalipsky S: Targeting folate receptor with folate linked to extremities of poly (ethylene glycol)-grafted liposomes: in vitro studies. Bioconjug Chem 1999, 10:289-298.

16. Tyagi N, Ghosh PC: Folate receptor mediated targeted delivery of ricin entrapped into sterically stabilized liposomes to human epidermoid carcinoma (KB) cells: Effect of monensin intercalated into folate-tagged liposomes. Eur J Pharm Sci 2011, 43:343-353.

17. Leamon CP, Weigl D, Hendren RW: Folate copolymer-mediated transfection of cultured cells. Bioconjug Chem 1999, 10:947-957.

18. Reddy JA, Dean D, Kennedy MD, Low PS: Optimization of folate-conjugated liposomal vectors for folate receptor-mediated gene therapy. J Pharm Sci 1999, 88:1112-1118.

19. Reddy JA, Low PS: Enhanced folate receptor mediated gene therapy using a novel pH-sensitive lipid formulation. J Control Release 2000, 64:27-37.

20. Reddy JA, Low PS: Enhanced folate receptor mediated gene therapy using a novel $\mathrm{pH}$-sensitive lipid formulation. J Control Release 2000, 64:27-37.

21. Sohara Y, Shimada H, Scadeng M, Pollack H, Yamada S, Ye W, Reynolds CP, DeClerck YA: Lytic bone lesions in human neuroblastoma xenograft involve osteoclast recruitment and are inhibited by bisphosphonate. Cancer Res 2003, 63:3026-3031.

22. Zhao H, Cai W, Li S, Da Z, Sun H, Ma L, Lin Y, Zhi D: Establishment and characterization of xenograft models of human neuroblastoma bone metastasis. Childs Nerv Syst 2012, 28:2047-2054.

23. Galderisi U, Di Bernardo G, Cipollaro M, Peluso G, Cascino A, Cotrufo R, Melone MAB: Differentiation and apoptosis of neuroblastoma cells: role of N-myc gene product. J Cell Biochem 1999, 73:97-105.

24. Phoenix TN, Gilbertson RJ: There's a time and a place for MYCN. Cancer Cell 2012, 21:593-595.

25. Huang R, Cheung NKV, Vider J, Cheung IY, Gerald WL, Tickoo SK, Holland EC, Blasberg RG: MYCN and MYC regulate tumor proliferation and tumorigenesis directly through BMI1 in human neuroblastomas. FASEB J 2011, 25:4138-4149.

26. Corvi R, Savelyeva L, Breit S, Wenzel A, Handgretinger R, Barak J, Oren M, Amler L, Schwab M: Non-syntenic amplification of MDM2 and MYCN in human neuroblastoma. Oncogene 1995, 10:1081.
27. Kang JH, Rychahou PG, Ishola TA, Qiao J, Evers BM, Chung DH: MYCN silencing induces differentiation and apoptosis in human neuroblastoma cells. Biochem Biophys Res Commun 2006, 351:192-197.

28. Nara K, Kusafuka T, Yoneda A, Oue T, Sangkhathat S, Fukuzawa M: Silencing of MYCN by RNA interference induces growth inhibition, apoptotic activity and cell differentiation in a neuroblastoma cell line with MYCN amplification. Int J Oncol 2007, 30:1189-1196.

29. Woo CW, Tan F, Cassano H, Lee JH, Lee KC, Thiele CJ: Use of RNA interference to elucidate the effect of MYCN on cell cycle in neuroblastoma. Pediatr Blood Cancer 2008, 50:208-212.

30. Bell E, Premkumar R, Carr J, Lu X, Lovat PE, Kees UR, Lunec J, Tweddle DA: The role of MYCN in the failure of MYCN amplified neuroblastoma cell lines to G. Cell Cycle 2006, 5:2639-2647.

31. Biewenga JE, Destrée OHJ, Schrama LH: Plasmid-mediated gene transfer in neurons using the biolistics technique. J Neurosci Methods 1997, 71:67-75.

doi:10.1186/1475-2867-13-65

Cite this article as: Zhu et al:: Target delivery of MYCN siRNA by folate-nanoliposomes delivery system in a metastatic neuroblastoma model. Cancer Cell International 2013 13:65.

\section{Submit your next manuscript to BioMed Central and take full advantage of:}

- Convenient online submission

- Thorough peer review

- No space constraints or color figure charges

- Immediate publication on acceptance

- Inclusion in PubMed, CAS, Scopus and Google Scholar

- Research which is freely available for redistribution
C Biomed Central 